32. Chen C, Gettes LS, Katzung BG: Effect of lidocaine on steady-state characteristics and recovery kinetics of $\mathrm{dV} / \mathrm{dt}$ $\max$ in guinea pig ventricular myocardium. Circ Res 37:20, 1975.

33. El-Sherif N, Scherlag BJ, Lazzara R, Hope RR: Reentrant ventricular arrhythmias in the late myocardial infarction period. A mechanism of action of lidocaine. Circulation 56:395, 1977

34. Ruskin JN, Akthar M, Foster JR, Damato AN: The effect of lidocaine on reentry within the His-Purkinje system in man (abstr). Circulation 52:II-137, 1975.

35. Charlier R: Cardiac actions in the dog of a new antagonist of adrenergic excitation which does not produce competitive blockade of adrenoreceptors. Br J Pharmacol 39:668, 1970.

36. Cóté P, Bourassa MG, Delaye J, Janin A, Froment R, David $P$ : Effects of amiodarone on cardiac and coronary hemodynamics and on myocardial metabolism in patients with coronary artery disease. Circulation 59:1165, 1979.

37. Horowitz LN, Josephson ME, Farshidi A, Spielman SR, Michelson EL, Greenspan AM: Recurrent sustained ventricular tachycardia. III. Role of the electrophysiologic study in selection of antiarrhythmic regimens. Circulation 58:986, 1978.

\title{
Antidysrhythmic actions of meobentine sulfate
}

The antiarrhythmic efficacy of meobentine sulfate, a bethanidine derivative lacking inhibitory effects on adrenergic neuronal function, was assessed in three canine models. Intranvenous meobentine sulfate, administered in dosages of $5.0,10,0$, and $20.0 \mathrm{mg} / \mathrm{kg}$, produced a dose-related increase in the ventricular fibrillation threshold (VFT) under nonischemic conditions $(7.6 \pm 1.8 \mathrm{~mA}$ vs $37.8 \pm 8.6 \mathrm{~mA})(20 \mathrm{mg} / \mathrm{kg} ; p<0.05)$ and during regional myocardial ischemia $(5.6 \pm 1.5 \mathrm{~mA}$ vs $41.8 \pm 9.1 \mathrm{~mA})(20 \mathrm{mg} / \mathrm{kg} ; p<0.05)$. The VFT was also increased in the presence of chronic ischemic injury $(6.4 \pm 1 \mathrm{~mA}$ to $31 \pm 10 \mathrm{~mA})(20 \mathrm{mg} / \mathrm{kg} ; \boldsymbol{p} 0.05)$. In the conscious dog, 4 days after an anterior myocardial infarction, programmed electrical stimulation (PES) produced nonsustained ventricular tachycardla (VT) In flve dogs. After meobentine sulfate administration, eight of nine animals had sustained $V T$ and one animal developed ventricular fibrillation (VF). At a dose of $20 \mathrm{mg} / \mathbf{k g}$, there was prolongation of the cycle length of the VT (169 $\pm 11 \mathrm{msec}$ to $237 \pm 20 \mathrm{msec}$ ), prolongation of the QRS duration (58 $\pm 2.6 \mathrm{msec}$ to $71 \pm 3.7 \mathrm{msec}$ ), and prolongation of the delay in epicardial activation. There was an enhanced potentlal after meobentine administration for programmed stimulation to produce ventricular arrhythmias with the introduction of fewer premature impulses. In the third canine model, conscious dogs with a previous anterior myocardial infarction developed VF in response to electrically induced left circumflex coronary artery injury. Meobentine $(20 \mathrm{mg} / \mathrm{kg})$ failed to prevent VF in eight of eight dogs. These results suggest that while meobentine sulfate signiflcantly Increases the electrical VFT, It does not protect the conscious canine from the induction of ventricular tachyarrhythmias in response to PES, and it does not prevent VF in a conscious canine model of sudden coronary death. The data would suggest that meobentine will not be effective in preventing sudden death in patients with ischemic heart disease. (AM HEART J 107:1117, 1984.)

John M. Zimmerman, M.D., Eugene Patterson, Ph.D., Bertram Pitt, M.D., and Benedict Lucchesi, Ph.D., M.D. Ann Arbor, Mich.

Meobentine sulfate is a structural analogue of bethanidine. It has been suggested that this drug has

From the Department of Pharmacology and the Department of Internal Medicine (Division of Cardiology), The University of Michigan Medical School.

Supported by the National Institutes of Health, Heart, Lung, and Blood Institute, Grant No. HL-05806.

Received for publication Oct. 13, 1983; accepted Nov. 1, 1983.

Reprint requests: Benedict R. Lucchesi, Ph.D., M.D., Department of Pharmacology, M7423 Medical Science Building 1, The University of Michigan Medical School, Ann Arbor, MI 48109. the antidysrhythmic properties of bretylium but does not produce catecholamine release or adrenergic neuron blockade., ${ }^{1,2}$ Work by Wastilla et al. ${ }^{1}$ and Michelson et al. ${ }^{3,4}$ has shown meobentine sulfate to increase the ventricular fibrillation threshold (VFT), thereby suggesting that it might be an effective antifibrillatory agent.

The work done by Gang et al. ${ }^{5}$ has suggested that there is a reduction in the VFT in the canine heart after myocardial infarction when ventricular tachycardia (VT) can be induced by programmed stimu- 
lation. It has not, however, been demonstrated that all drugs which raise VFT are efficacious in abolishing inducible VT and in preventing the spontaneous development of malignant ventricular arrhythmias. The purpose of this study was to learn more about the antidysrhythmic properties of meobentine sulfate and the relationship between the VFT, the induction of ventricular dysrhythmias with programmed stimulation, and the spontaneous development of lethal ventricular dysrhythmias. Toward this end we examined the actions of meobentine sulfate upon the VFT in the anesthetized dog, upon programmed electrical stimulation (PES) in conscious dogs after myocardial infarction, and upon the spontaneous development of ventricular fibrillation (VF) in a conscious canine model of "sudden coronary death." ${ }^{6-9}$

\section{METHODS}

\section{VFT determination: Model I}

Animal preparation. Male mongrel dogs, weighing between 10 and $18 \mathrm{~kg}$, were anesthetized with intravenous sodium pentobarbital $(30 \mathrm{mg} / \mathrm{kg})$. A cuffed endotracheal tube was inserted and the animals were ventilated with room air by means of a Harvard respirator. The rate and tidal volume were adjusted to maintain arterial $\mathrm{pH}, \mathrm{PCO}_{2}$ and $\mathrm{PO}_{2}$ within normal physiologic limits. Arterial pH, $\mathrm{PCO}_{2}$, and $\mathrm{Po}_{2}$ were measured with an Instrumentation Laboratories blood gas analyzer. The left common carotid artery and left external jugular vein were isolated and cannulated. The arterial pressure was continuously monitored by means of a Statham P23DC pressure transducer. A left thoracotomy was performed in the fourth intercostal space and the heart was suspended in a pericardial cradle. The left anterior descending coronary artery (LAD) was dissected free distal to the second or third diagonal branch and a loose ligature was passed beneath the artery.

Electrode placement. A bipolar clip was placed on the right atrial appendage and the heart rate was controlled with atrial pacing (4 msec duration stimuli, $2 \times$ diastolic threshold). A bipolar plunge electrode (25-gauge stainless steel, $4 \mathrm{~mm}$ in length, $2 \mathrm{~mm}$ apart) was placed in the left ventricular myocardium in the region perfused by the left circumflex coronary artery. The left ventricular refractory period and the excitation threshold were determined from this electrode. A bipolar electrode consisting of $1 \mathrm{~mm}$ diameter silver electrodes embedded $3 \mathrm{~mm}$ apart in dental acrylic was sewn onto the right ventricular surface.

Determination of VFT. VFT was determined as previously described. ${ }^{9}$ The ventricular rate was maintained constant with atrial pacing while determination of the VFT was performed. Ventricular excitation thresholds (the minimum current necessary to produce a conducted ventricular beat at a stimulus duration of 4 msec delivered $300 \mathrm{msec}$ after the $\mathrm{R}$ wave of the lead II ECG), ventricular refractory periods (the longest $R$ to simulus interval at which a $2 \times$ diastolic threshold stimulus, $4 \mathrm{msec}$ in dura- tion, failed to produce a conducted ventricular beat), and ventricular activation (the interval between the $Q$ wave and local myocardial activation) were obtained immediately before determination of the VFT. To determine the VFT, trains of $4 \mathrm{msec}$ duration square-wave pulses $(60 \mathrm{~Hz}$, $200 \mathrm{msec}$ duration) were delivered to the right ventricle 50 msec after the peak of the $R$ wave. The output of a Grass S-88 stimulator (Grass SIU-5 stimulus isolation and Grass constant current unit) was triggered from the $R$ wave of the lead II ECG by using a Tektronix 565 oscilloscope and type 3 A8 operational amplifier. The current intensity was increased in $1.0 \mathrm{~mA}$ increments to $10 \mathrm{~mA}$, then in $2 \mathrm{~mA}$ increments to $20 \mathrm{~mA}$, and $5 \mathrm{~mA}$ increments to $55 \mathrm{~mA}$ until VF ensued. Three trials were performed at each current intensity with 8 - to 10 -beat intervals between trials. The VFT was defined as the current intensity producing VF. Immediately after VF occurred the heart was defibrillated by means of a capacitor-discharge direct-current defibrillator charged to 20 joules.

The VFT was determined under nonischemic conditions and, after a 15-minute recovery period, reassessed during a 2-minute occlusion of the LAD. After a 15minute recovery period interval, meobentine, $5 \mathrm{mg} / \mathrm{kg}$, was infused intravenously over a 30-minute period. Electrophysiologic testing was repeated 30 minutes later. Additional cumulative doses of 10 and $20 \mathrm{mg} / \mathrm{kg}$ were administered in an identical manner and electrophysiologic testing was repeated. VFTs also were determined in the canine, 4 days after myocardial infarction, by means of identical methods. Myocardial infarction was produced as described in the section below.

PES in the conscious dog during the subacute phase of myocardial infarction: Model II

Animal preparation. Male mongrel dogs, weighing 12 to $22 \mathrm{~kg}$, were anesthetized with intravenous sodium pentobarbital, $30 \mathrm{mg} / \mathrm{kg}$. A cuffed endotracheal tube was inserted and the animal ventilated with room air by means of a Harvard respirator. By means of an aseptic technique, the left external jugular vein and left common carotid artery were isolated and cannulas were inserted. The cannulas were passed subcutaneously to the back of the neck and surfaced through a small incision. A left thoracotomy was performed in the fourth intercostal space and the anterior surface of the heart was exposed. The heart was then suspended in a pericardial cradle. Using blunt dissection, the LAD was dissected free at the border of the atrial appendage. A 19-gauge needle with a blunted end was placed parallel to the coronary artery, and a suture was passed around both the coronary artery and the needle. The suture was tied securely and the needle withdrawn, producing a critical stenosis. The artery then was occluded by using a snare formed from a loop of silicone rubber tubing passed through a blunt-ended polyethylene tube. After 2 hours of regional ischemia, blood flow was restored through the stenosed vessel.

Electrode placement. A bipolar electrode was sewn onto the surface of the left atrial appendage. A second bipolar plunge electrode (28-gauge stainless steel, 5 to $7 \mathrm{~mm}$ in length) was placed in the right ventricular outflow tract 
with the exposed electrode tip placed in the interventricular septum. Bipolar composite electrodes were placed on the epicardial surface of the left ventricle. One bipolar composite electrode was placed over the normal myocardium and the second was placed over the ischemic and infarcted myocardium. Correct placement of the bipolar composite electrodes was confirmed at autopsy. The electrode wires were exteriorized through the chest. The chest incision was closed and the dogs were given ampicillin, 6 $\mathrm{mg} / \mathrm{kg}$ intramuscularly twice daily, and permitted to recover from anesthesia.

Electrophysiologic studies. Four days after myocardial infarction, the animals were returned to the laboratory. They were conscious and resting comfortably, supported in a sling. Ventricular premature stimuli (4 msec duration square-wave impulses, twice distolic threshold) were applied to the interventricular septum with the use of a Grass S-88 stimulator and SIU-5 stimulus isolation unit. A Tektronix 565 oscilloscope and operational amplifier were used to trigger the stimulus from the $\mathrm{R}$ wave of the lead II ECG.

The PES procedure is outlined as follows. (1) Single premature ventricular stimuli $\left(\mathrm{S}_{2}\right)$ were introduced during normal sinus rhythm at decreasing $10 \mathrm{msec}$ intervals from 350 msec until ventricular refractoriness occurred. (2) Double premature ventricular stimuli $\left(S_{2}\right.$ and $\left.S_{3}\right)$ were introduced during normal sinus rhythm at decreasing 10 msec intervals for $S_{2}$ stimuli from $350 \mathrm{msec}$ until ventricular refractoriness occurred with $S_{2}$ to $S_{3}$ intervals of 200 , $180,170,160,150,140,135$, and $130 \mathrm{msec}$. (3) Triple premature ventricular stimuli $\left(\mathbf{S}_{2}, \mathbf{S}_{3}\right.$, and $\left.\mathbf{S}_{4}\right)$ were introduced during normal sinus rhythm at decreasing $10 \mathrm{msec}$ intervals for $S_{2}$ stimuli until ventricular refractoriness occurred with $S_{2}$ to $S_{3}$ and $S_{3}$ to $S_{4}$ intervals as stated previously. (4) Intermittent ventricular pacing $(2 \times$ diastolic threshold) at rates to $360 \mathrm{bpm}$ was applied. Previous work has shown that this method of PES fails to produce ventricular dysrhythmias in sham-operated animals without ischemic myocardial injury. ${ }^{10}$

The arterial blood pressure was measured with a Statham P23DC pressure transducer. The lead II ECG and arterial pressure were recorded continuously on a Grass model 7 polygraph. The composite bipolar electrodes and lead II ECG were stored on magnetic tape with the use of a Lockheed FM tape recorder and permanent records were obtained by means of a Honeywell oscillographic recorder. The ventricular refractory period of normal ventricular myocardium was measured at $2 \times$ diastolic threshold (4 msec duration stimulus). After determination of baseline electrophysiologic values and reproduction of sustained or nonsustained VT in triplicate, meobentine sulfate, $5 \mathrm{mg} /$ $\mathrm{kg}$, was administered intravenously over a 30 -minute period. Electrophysiologic testing was repeated 30 minutes later. Additional cumulative doses of meobentine, 10 and $20 \mathrm{mg} / \mathrm{kg}$, were administered in an identical manner and electrophysiologic testing was repeated.

Conscious canine model of sudden coronary death: Model III

Animal preparation. Male mongrel dogs, weighing

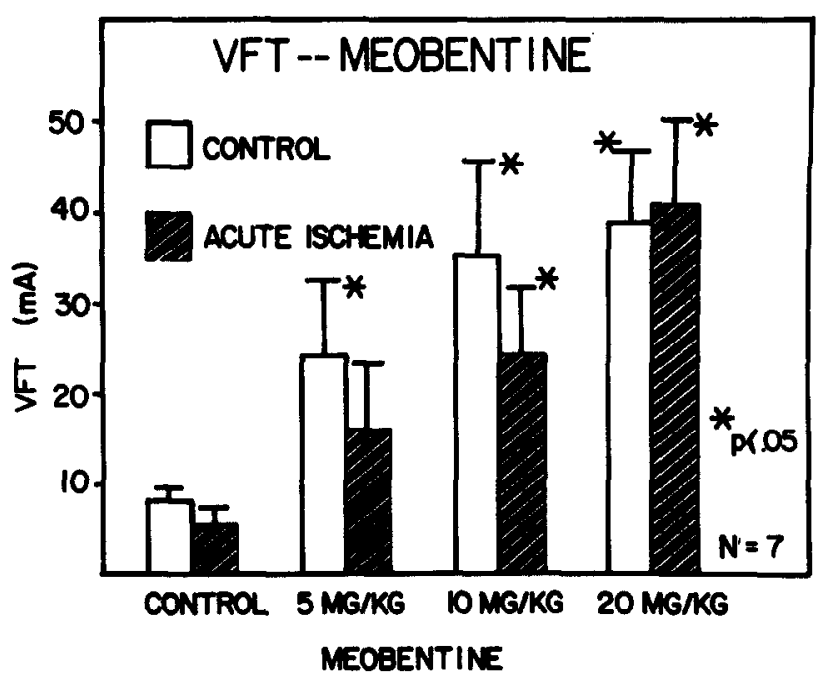

Fig. 1. Ventricular fibrillation threshold (VFT) measured under nonischemic conditions and after a 2-minute occlusion of the LAD. Meobentine sulfate resulted in a statistically significant increase in VFT in all dosages except during acute ischemia at the $5 \mathrm{mg} / \mathrm{kg}$ dose.

between 13 and $23 \mathrm{~kg}$, were anesthetized with intravenous sodium pentobarbital, $30 \mathrm{mg} / \mathrm{kg}$. A cuffed endotracheal tube was inserted and the animal ventilated with room air by means of a Harvard respirator. Aseptic surgical technique was employed for insertion of cannulas in the jugular vein and carotid artery. A left thoracotomy was performed in the fourth intercostal space and the heart was suspended in a pericardial cradle. Both the LAD and left circumflex coronary arteries were dissected free from the underlying myocardium, the LAD approximately 1 to $1.5 \mathrm{~cm}$ from its origin and the circumflex coronary artery approximately $1 \mathrm{~cm}$ from its origin. Myocardial infarction within the distribution of the LAD was produced as previously described.

Intracoronary electrode placement. A 30-gauge Tefloncoated silver wire was fashioned with $3 \mathrm{~mm}$ of the tip of a 25-gauge hypodermic needle secured on the wire's lead end which served to aid in the penetration of the arterial wall. The wire was inserted through the wall of the left circumflex coronary artery so that approximately 2 to 3 $\mathrm{mm}$ of the bare wire-needle-tip assembly was within the vessel lumen and in contact with the intimal surface. The wire was secured to the epicardium with two sutures. The distal end of the silver wire was exteriorized and would subsequently serve to deliver an anodal current of $150 \mu \mathrm{A}$ to the intimal surface of the left circumflex coronary artery. A silver disk electrode was sutured to the subcutaneous tissue and completed the electrical circuit, which consisted of a $9 \mathrm{~V}$ nickel-cadmium battery and a 250,000 ohm potentiometer placed in series so as to allow adjustment of the current flow. A bipolar plunge electrode consisting of a 25-gauge insulated stainless steel wire, 4 $\mathrm{mm}$ in length and separated by $2 \mathrm{~mm}$, was placed in the ventricular septum adjacent to the right ventricular out- 


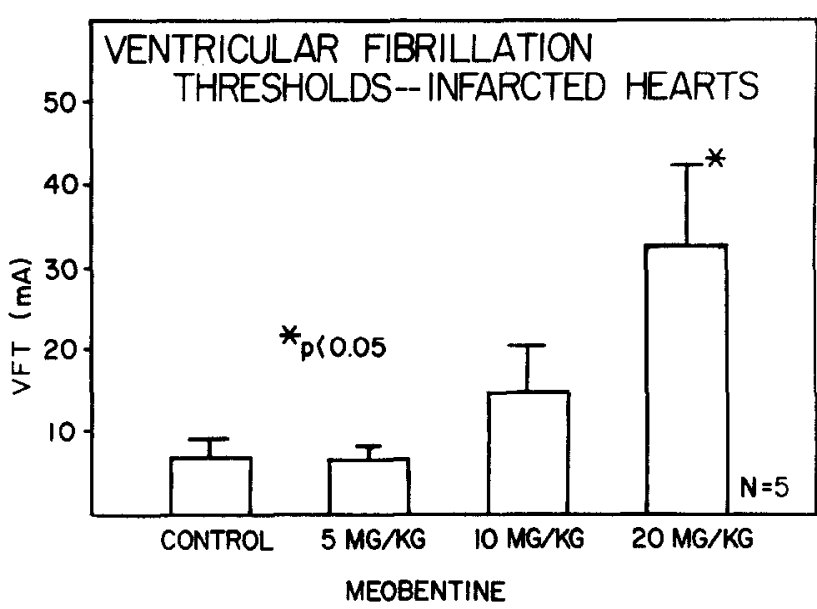

Fig. 2. Ventricular fibrillation threshold (VFT) was measured in anesthetized dogs 4 days after myocardial infarction. There was a statistically significant increase in VFT at the $20 \mathrm{mg} / \mathrm{kg}$ dose.

flow tract. The surgical incision was closed and the animals were given $6 \mathrm{mg} / \mathrm{kg}$ of ampicillin intramuscularly and allowed to recover from the surgical procedures.

Experimental procedure. Four days after the thoracotomy, the animals were returned to the laboratory and studied while conscious, unsedated, and resting comfortably in a sling. PES was performed on all animals as described previously. After PES testing was completed, the animals were assigned randomly to one of two groups. One group received meobentine sulfate, $20 \mathrm{mg} / \mathrm{kg}$ intravenously administered over a 30 -minute period, while the other group received an equal volume of the $0.9 \%$ sodium chloride diluent. PES was repeated in the animals which received meobentine sulfate. After completion of programmed stimulation, the animals were placed in a $3 \times 6$ $\mathrm{m}$ isolation room. The lead II ECG was transmitted through telemetry and stored on FM tape for subsequent analysis. The radiotelemetry transmitter, potentiometer, and $9 \mathrm{~V}$ nickel-cadmium battery were contained in a $10 \times 15 \times 5 \mathrm{~cm}$ box placed securely in a nylon vest, thus allowing the animal freedom of movement. Once adequate baseline recordings were obtained, a continuous direct anodal current of $150 \mu \mathrm{A}$ was applied to the intimal surface of the left circumflex coronary artery. An observer continuously monitored the transmitted data to detect changes in cardiac rhythm and ST segment shifts.

Myocardial infarct size determinations. The techniques were similar to those previously described. ${ }^{9}$ After the animals were killed the heart was excised. In animals in the programmed stimulation study group, cannulas were inserted into the LAD at the point of occlusion and into the root of the aorta. Triphenyltetrazolium chloride $(0.5 \%$ weight/volume), a histochemical stain which forms a distinctive red color in the presence of intracellular dehydrogenases, was infused directly into the LAD at the site of the previous occlusion. The histochemical stain demarcates surviving myocardium in the area at risk for

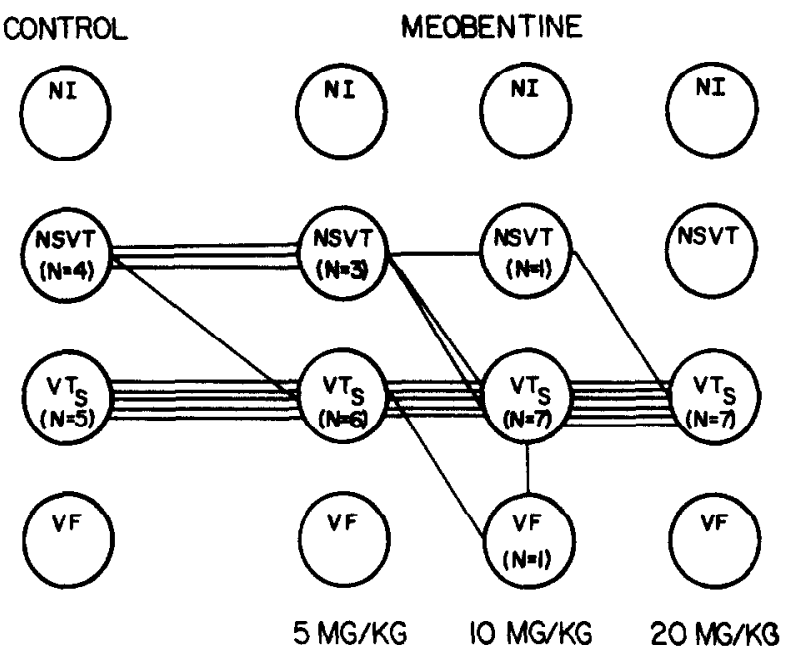

Fig. 3. Ventricular tachyarrhythmias induced by PES at increasing dosages of meobentine sulfate. The number of animals having no induced tachyarrhythmias (NI), nonsustained ventricular tachycardia (NSVT), sustained ventricular tachycardia (VTs), and ventricular fibrillation $(V F)$ is shown before and after the administration of meobentine. The connecting lines show the responses of individual animals over the course of the experiment.

infarction. Evans blue dye $(0.5 \%$ weight/volume) was infused simultaneously into the root of the aorta to demarcate the remaining myocardium. Both solutions were delivered under equal pressure $(100 \mathrm{~mm} \mathrm{Hg})$ to allow for clear delineation of the region supplied by their respective coronary arteries and to eliminate flow across collateral vessels. Nonsurviving infarcted tissue within the area at risk of infarction is distinguished from surviving tissue by its pale appearance. Infarcted mass and area at risk of infarction were determined gravimetrically.

In the conscious canine model of sudden coronary death, in which VF occurred, the heart was removed and the left circumflex coronary artery carefully dissected and examined for the presence of thrombus. Thrombus mass was determined gravimetrically. The heart was then sectioned into $1 \mathrm{~cm}$ rings from apex to base, parallel to the atrioventricular groove. The transverse sections were placed into $0.5 \%$ triphenyltetrazolium chloride in $0.01 \mathrm{M}$ phosphate buffer (pH 7.4) and infarct size was determined gravimetrically.

Statistics. Data are expressed as the mean \pm SEM. Differences within a group were analyzed by one-way analysis of variance. Differences in survival between control and meobentine groups were analyzed with Fisher's exact test. $p<0.05$ was the criterion for significance.

\section{RESULTS}

VFT determinations. Meobentine sulfate dosages of $5.0,10.0$, and $20.0 \mathrm{mg} / \mathrm{kg}$ significantly increased VFTs determined in the absence of myocardial ischemia and during acute coronary artery occlusion 


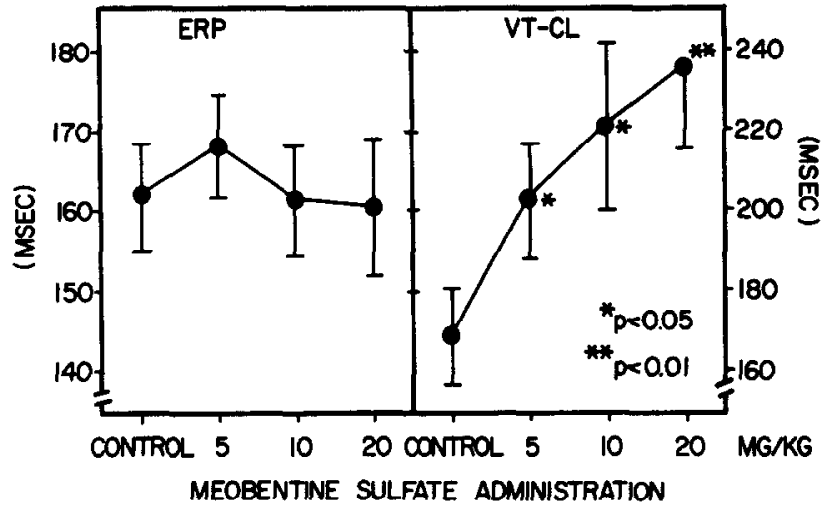

Fig. 4. Effects of increasing dosages of meobentine sulfate on the ventricular effective refractory period (ERP) and the cycle length of the ventricular tachycardia (VT$C L$ ) measured during PES in the conscious dog during the subacute phase of myocardial infarction. There was a statistically significant increase in the cycle length of the VT at all dosages.

(Fig. 1). There was also an increase in the VFT of animals with previous anterior myocardial infarctions at dosages of $20 \mathrm{mg} / \mathrm{kg}$ (Fig. 2). A significant increase in the myocardial conduction time was noted at the $20 \mathrm{mg} / \mathrm{kg}$ dose, from a predrug duration of $17.5 \pm 1.5 \mathrm{msec}$ to $23.1 \pm 1.6 \mathrm{msec} ; p<0.05$. There was no change in the excitation thresholds or in the ventricular effective refractory period.

PES in the conscious dog during subacute phase of myocardial infarction. PES was performed in 10 consecutive dogs 4 days after myocardial infarction. Before the administration of meobentine sulfate, PES produced nonsustained VT in four animals and sustained VT in six animals. After the administration of meobentine sulfate in cumulative dosages of 5,10 , and $20 \mathrm{mg} / \mathrm{kg}$, each of the animals which had displayed nonsustained VT now demonstrated sustained VT. At a dose of $20 \mathrm{mg} / \mathrm{kg}$, all animals tested demonstrated sustained ventricular dysrhythmias (Fig. 3). Slower rates of ventricular pacing and/or fewer premature ventricular impulses were necessary to produce ventricular tachyarrhythmias after the administration of meobentine sulfate.

The cycle length of the VT was prolonged by meobentine sulfate in a dose-related manner; it changed from a predrug mean cycle length of $169 \pm$ $11 \mathrm{msec}$ to $205 \pm 17 \mathrm{msec}$ at $5 \mathrm{mg} / \mathrm{kg}(p<0.05)$, to $221 \pm 22 \mathrm{msec}$ at $10 \mathrm{mg} / \mathrm{kg}(p<0.05)$, and to $237 \pm$ $20 \mathrm{msec}$ at $20 \mathrm{mg} / \mathrm{kg}(p<0.01)$ (Fig. 4). The QRS duration lengthened in a dose-related manner after meobentine sulfate, with a predrug mean duration of $58 \pm 3 \mathrm{msec}$ increasing to $71 \pm 4$ at a dosage of 20 $\mathrm{mg} / \mathrm{kg}$. The prolongation of QRS duration at a

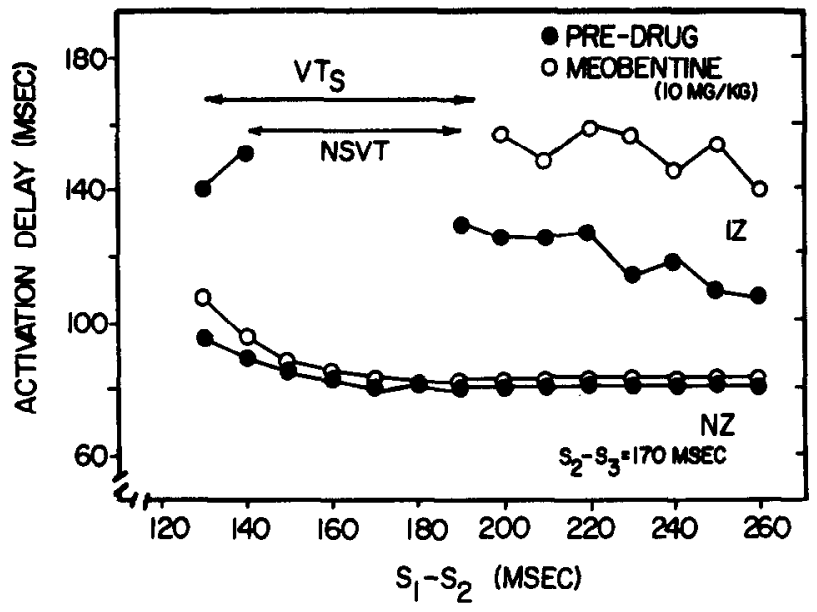

Fig. 5. Electrophysiologic effect of meobentine $(10 \mathrm{mg} /$ $\mathrm{kg}$ ). Before meobentine administration, epicardial activation delays were produced by PES within both normal (NZ) and ischemically injured (IZ) myocardium. The delay was always greater in the ischemically injured zone. Meobentine administration resulted in prolongation of the epicardial delay in the normal and ischemically injured zone for all $S_{1}, S_{2}$ coupling intervals. Prior to the administration of meobentine, an epicardial activation delay of $158 \mathrm{msec}$, produced with an $\mathrm{S}_{2}-\mathrm{S}_{3}$ interval of 170 and a $S_{1} S_{2}$ interval of 130 to $140 \mathrm{msec}$, resulted in the induction of nonsustained ventricular tachycardia $(N S V T)$. After meobentine administration $(10 \mathrm{mg} / \mathrm{kg})$ a conduction delay of 160 msec, produced with an $S_{2}-S_{3}$ coupling interval of $170 \mathrm{msec}$ and an $S_{1}-S_{2}$ coupling interval of less than $200 \mathrm{msec}$, resulted in sustained ventricular tachycardia (VTs).

dosage of 10 and $20 \mathrm{mg} / \mathrm{kg}$ reached statistical significance $(p<0.05)$. There was no prolongation in either the $\mathrm{PR}$ or $\mathrm{QT}_{\mathrm{c}}$ duration at any drug dosage tested.

Bipolar composite electrodes placed over the epicardial surface of the left ventricle in both a normal and ischemically injured region were used to measure epicardial activation delays produced by PES. The delay was always greater in the ischemically injured zone. Meobentine sulfate produced a prolongation of the epicardial activation delay in the normal and to a greater extent in the ischemically injured zone for all $S_{1}, S_{2}$ coupling intervals (Fig. 5).

Conscious canine model of sudden coronary death. PES in control animals produced nonsustained VT in five dogs, sustained VT in four dogs, and VF in one dog, three dogs were not inducible. In dogs pretreated with meobentine, PES produced nonsustained VT in three dogs and sustained VT in three dogs; two dogs were not inducible. In the control dogs, ST segment elevation or depression in excess of $0.3 \mathrm{mV}$ developed in all 13 animals at $92 \pm 13$ 


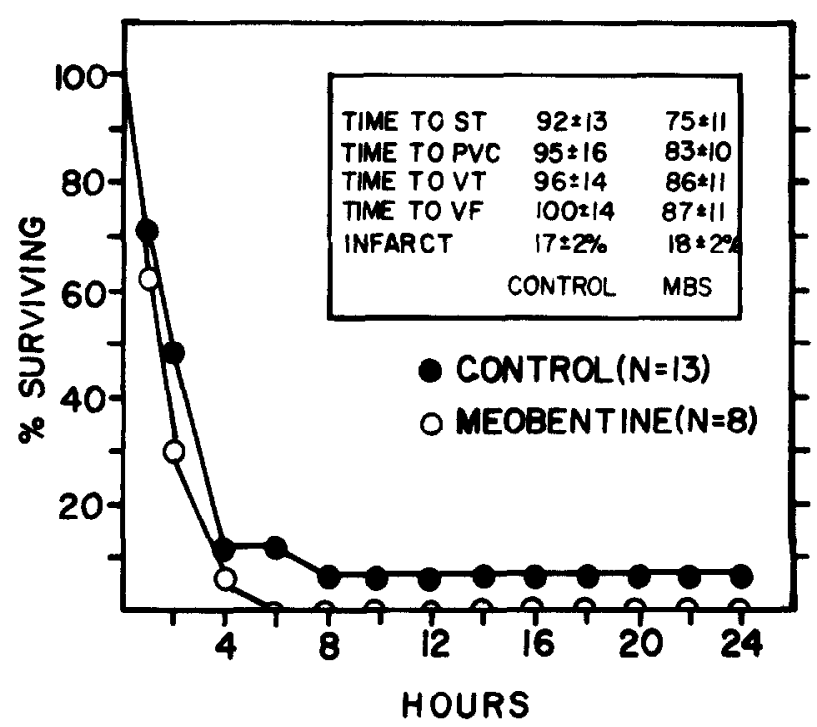

Fig. 6. Survival rate of saline- and meobentine-treated animals after left circumflex intimal injury. Also depicted is the time of ST segment change, time of first ventricular premature beat $(P V C)$, time of onset of ventricular tachycardia $(V T)$, time of development of ventricular fibrillation $(V F)$, and myocardial infarct size in the meobentinetreated and control groups.

minutes after initiation of anodal current flow to the intimal surface of the left circumflex coronary artery. Premature ventricular contractions were manifested at $95 \pm 16$ minutes followed by VT at $96 \pm 14$ minutes, with VF developing at $100 \pm 14$ minutes in 12 of 13 animals. ST segment changes in the meobentine-treated group developed at $75 \pm 11$ minutes. Premature ventricular beats developed at $83 \pm 10$ minutes. VT developed at $86 \pm 11$ minutes and VF developed at $87 \pm 11$ minutes. Each of the eight dogs in the meobentine-treated group developed VF (Fig. 6).

Myocardial infarct size within the distribution of the LAD was not different between the meobentinetreated $(19 \pm 2 \%)$ and the diluent-treated control group $17 \pm 2 \%$ ). Myocardial infarction as detected by triphenyltetrazolium staining for cellular dehydrogenase activity was not detected within the left circumflex coronary artery distribution of the control or meobentine-treated animals which terminated suddenly as a result of VF.

Hemodynamics. After infusion of meobentine sulfate over 30 minutes at dosages of 5,10 , and 20 $\mathrm{mg} / \mathrm{kg}$, we noted no change in heart rate or blood pressure. We did note, however, that the rapid infusion of meobentine sulfate resulted in a transient hypotensive response. In all cases when greater than $20 \mathrm{mg} / \mathrm{kg}$ of meobentine was infused, irrevers- ible hypotension and death resulted, thereby limiting our ability to explore the dose-response relationship any further.

\section{DISCUSSION}

Increased VFT. Meobentine sulfate is a structural analogue of bethanidine. It has been suggested that this drug has the antidysrhythmic properties of bretylium because, like bretylium, it increases VFT. ${ }^{11-14}$ Wastilla et al. ${ }^{1}$ have shown meobentine sulfate to be effective in preventing VF after coronary artery occlusion and release and to significantly increase VFT in dogs at dosages of 20 and $40 \mathrm{mg} / \mathrm{kg}$. Michelson et al..$^{3,4}$ found meobentine sulfate to be effective in preventing VF induced by pacing and programmed stimulation by using anesthetized dogs studied several days after a two-stage LAD occlusion and reperfusion. In this experiment we also found meobentine sulfate to be effective in increasing the VFT under nonischemic conditions, during regional myocardial ischemia, and in the presence of chronic ischemic injury.

There is, however, considerable question as to whether a drug's ability to increase the VFT alone can be used to assess the efficacy of an antiarrhythmic drug. ${ }^{9,15-17}$ Therefore, other animal models which may more closely simulate the conditions leading to sudden coronary death in humans have been employed to assess the potential role of meobentine sulfate.

Canine models of sudden coronary death. It has been shown that patients resuscitated from a cardiac arrest when tested with PES will have reentrant ventricular arrhythmias, which are identical to the spontaneously occurring arrhythmias previously observed. ${ }^{18-20}$ Antiarrhythmic drugs, which can suppress the induction of the ventricular tachyarrhythmias in response to PES, have been shown to be successful in preventing the recurrence of the ventricular tachyarrhythmia during chronic therapy. ${ }^{18,20}$ The animal model of PES 3 to 14 days after myocardial infarction has been demonstrated to closely resemble the ventricular tachyarrhythmias produced in patients. ${ }^{21-24}$ However, in the use of PES an artificial stimulus is again necessary for induction of ventricular arrhythmias. Recently Patterson et al., ${ }^{6}$ Romson et al., ${ }^{7}$ and Schwartz and Stone ${ }^{25}$ have described animal models for the development of VF in a physiologic setting without anesthesia and without being dependent on an external provocative stimulus for the development of VT and/or VF. It was found that if an animal was prepared with a myocardial infarction secondary to occlusion and 
reperfusion of the LAD, the addition of an acute thrombotic or occlusive event in the left circumflex coronary artery would result in a high incidence of VF. This was in contrast to the development of VF in only $20 \%$ of dogs with an acute thrombotic occlusion of the left circumflex coronary artery but without previous ischemic injury in the region supplied by the LAD. In this model, amiodarone, nadolol, and bretylium have been found to be effective in preventing VF while bethanidine has not proved to be effective. ${ }^{9,26-28}$

Lack of antiarrhythmic effect. In these two models of the animals, mesobentine sulfate did not appear to be an effective antiarrhythmic agent. In the model of PES in the conscious dog during the subacute phase of myocardial infarction, meobentine sulfate did lengthen the VT cycle length in a dose-dependent manner. It did not, however, result in the prevention of ventricular arrhythmias. In fact, all animals with nonsustained VT induced by programmed stimulation prior to the drug had the development of sustained VT or VF after meobentine. Also, meobentine's administration enabled a less rigorous stimulation protocol to be used in inducing animals to the point of VT. In the conscious canine model of sudden coronary death, meobentine sulfate had no protective effect in any of the eight dogs, each of which died of VF.

Mechanisms of electrophysiologic actions. The mechanism of meobentine's action as an antiarrhythmic agent is largely unknown. Meobentine, unlike the chemically similar compounds bethanidine and bretylium, is known not to be an inhibitor of adrenergic neuronal function..$^{1,2}$ Michelson et al. ${ }^{3}$ noted that 4 to 6 days after a two-stage LAD occlusion and reperfusion, the ventricular refractory period increased with meobentine sulfate at a dosage of $20 \mathrm{mg} / \mathrm{kg}$ in the normal and ischemic zones but to a greater extent in the ischemic zone. They attributed meobentine's mechanism of action to its differential effect between the normal and ischemically injured myocardium.

In our model of PES the electrophysiologic actions of meobentine closely resembled those of lidocaine and procainamide..$^{24,30-32} \mathrm{We}$ noted that increasing dosages of meobentine resulted in an increase in the cycle length of the induced VT and there was an increase in the ease with which VT could be induced with increasing dosages of meobentine. Epicardial conduction delay measured with composite electrodes placed over the ischemically injured and normal zones showed increases in delay in both regions with increasing dosages of meoben- tine. There was also a statistically significant increase in QRS duration at the 10 and $20 \mathrm{mg} / \mathrm{kg}$ dosage, and an increase in myocardial conduction time at the $20 \mathrm{mg} / \mathrm{kg}$ dosage.

Conclusions. On the basis of the data from the four animal models, we found that while meobentine has significant effects in raising the VFT, it was ineffective in the conscious canine model of sudden coronary death and in the PES model. In the conscious canine model of sudden coronary death, none of the eight dogs treated with meobentine, $20 \mathrm{mg} / \mathrm{kg}$, was protected from VF. In the PES model, while the induced VT cycle length was prolonged in a doserelated manner, meobentine did not prevent the induction of VT and in fact facilitated its induction. The electrophysiologic actions of meobentine appear to be similar to type 1 antiarrhythmic agents. The drug prolongs the cycle length of inducible VT, prolongs epicardial conduction delay, and increases QRS duration. In many instances, the drug facilitates the induction of inducible VT. The data fail to show that meobentine sulfate has efficacy in preventing ventricular arrhythmias. We therefore feel that meobentine sulfate does not have significant potential as an agent to prevent sudden coronary death secondary to ischemic heart disease in humans.

REFERENCES

1. Wastilla WB, Copp FC, Walton E, Ellis CH, Maxwell RA: Meobentine sulfate $\left(b_{15} \mathrm{~N}\right.$-4-methoxybenzyl- $\mathrm{N}^{\prime} \mathrm{N}^{\prime}$-dimethylguanidine sulphate): A new antidysrhythmic agent. $J$ Pharm Pharmacol 33:594, 1981.

2. Burroughs Wellcome Co. Investigator's Brochure, Rhythmatine (meobentine sulfate and meobentine hydrochloride).

3. Michelson EL, Naito M, Dreifus D: Meobentine sulfate: Antiarrhythmic efficacy and mechanism of action in a chronic canine model of myocardial infarction susceptible to ventricular arrhythmias (abstr). Am J Cardiol 47:392, 1981.

4. Michelson EL: Burroughs Wellcome Co. Sponsored study"Antiarrhythmic efficacy of meobentine in a canine model of coronary artery occlusion and reperfusion." Burroughs Wellcome Co. Investigator's Brochure, Rhythmatine.

5. Gang ES, Bigger JT, Livelli FD: Model of chronic ischemic arrhythmias: The relation between electrically inducible ventricular tachycardia, ventricular fibrillation threshold and myocardial infarct size. Am J Cardiol 50:169, 1982.

6. Patterson E, Holland K, Eller B, Lucchesi B: Ventricular fibrillation resulting from ischemia at a site remote from previous myocardial infarction- -"a conscious canine model of sudden coronary death." Am J Cardiol 50:1414, 1982.

7. Romson JL, Haack DW, Lucchesi BR: Electrical induction of coronary artery thrombosis in the ambulatory canine: A model for in vivo evaluation of anti-thrombotic agents. Thromb Res 17:841, 1980.

8. Karagueuzian HS, Fenoglio JJ, Weiss MB, Wit AL: Protracted ventricular tachycardia induced by premature stimulation of the canine heart after coronary artery occlusion and reperfusion. Circ Res 44:833, 1979.

9. Patterson E, Lucchesi BR: Antifibrillatory actions of Nadolol. J Pharmacol Exp Ther 223:144, 1982.

10. Stewart JR, Gibson JK, Pitt B, Lucchesi BR: Post-infarction 
arrhythmias in the conscious dog: Electrophysiologic observations. Circulation 6O(Suppl II,II):159, 1979.

11. Bacaner M: Bretylium tosylate for suppression of induced ventricular fibrillation. Am J Cardiol 17:508, 1966.

12. Bacaner M: Treatment of ventricular fibrillation and other acute arrhythmias with bretylium tosylate. Am J Cardiol 21:530, 1968.

13. Bacaner MB, Schrienemachers D: Bretylium tosylate for suppression of ventricular fibrillation after experimental myocardial infarction. Nature (Lond) 220:494, 1968

14. Anderson JL, Patterson E, Conlon M, Pasyk S, Pitt B, Lucchesi BR: Kinetics of antifibrillatory effects of bretylium: Correlation with myocardial drug concentrations. Am J Cardiol 46:583, 1980 .

15. Hope RR, Scherlag BJ, El-Sherif N, Lazzara R: Ront phenomenon: A time for re-appraisal. Aust NZJ Med 7:109, 1977

16. El-Sherif N, Myerburg RJ, Scherlag BJ, Befler B, Aranda JM, Castellanos A, Lazzara R: Electrocardiographic characteristics of primary ventricular fibrillation. Value of the RMT phenomena. Br Heart J 38:405, 1976.

17. Zipes DP: Electrophysiologic mechanisms involved in ventricular fibrillation. Circulation 51,52(Suppl III):120, 1975.

18. Rustein JN, DiMarco JP, Garan H: Out of hospital cardiac arrest. Electrophysiologic observations and selections of longterm antiarrhythmic therapy. N Engl J Med 303:607, 1980.

19. Horowitz LN, Josephson ME, Farshidi A, Spielman SR, Greenspan AM: Recurrent sustained ventricular tachycardia. 3 . Role of the electrophysiologic study in selection of antiarrhythmic regimens. Circulation 58:986, 1978.

20. Josephson ME, Horowitz LN, Spielman SR, Greenspan AM: Electrophysiologic and hemodynamic studies in patients resuscitated from cardiac arrest. Am J Cardiol 46:948, 1980.

21. El-Sherif N, Hope R, Scherlag BJ, Lazzara R: Re-entrant ventricular arrhythmia in the late myocardial period. 2. Patterns of initiation and termination of re-entry. Circulation 55:702, 1977
22. Gibson JK, Lucchesi BR: Electrophysiologic actions of UM272 on reentrant ventricular arrhythmias in post-infarction canine myocardium. J Pharmacol Exp Ther 214:347, 1980.

23. Michelson EL, Spear JF, Moore EN: Electrophysiologic and anatomic correlates of sustained ventricular tachyarrhythmias in a model of chronic myocardial infarction. Am $J$ Cardiol 45:583, 1980 .

24. Davis J, Glassman R, Witt AL: Method for evaluating the effects of antiarrhythmic drugs on ventricular tachycardias with different electrophysiologic characteristics and different mechanisms in the infarcted canine heart. Am $\mathrm{J}$ Cardiol 49:1176, 1982

25. Schwartz PJ, Stone HL: The role of the autonomic nervous system in sudden coronary death. Ann NY Acad Sci 382:162, 1982

26. Patterson E, Eller B, Abrams G, Vasiliades J, Lucchesi B: Ventricular fibrillation in a conscious canine model of sudden coronary death: Prevention by acute and chronic amiodarone administration. Circulation. 68:857, 1983.

27. Patterson E, Lucchesi BR: Antifibrillatory actions of Nadolol. J Pharmacol Exp Ther 233:141, 1982.

28. Holland K, Patterson E, Lucchesi BR: Prevention of ventricular fibrillation by bretylium in a conscious canine model of sudden coronary death. AM HeART J 105:711, 1983.

29. Patterson E, Amalfitano DJ, Lucchesi BR: Development of ventricular tachyarrhythmias in the conscious canine during the recovery phase of experimental ischemic injury: Effect of bethanidine. Am Heak' J. (In press.)

30. El-Sherif N, Scherlag BJ, Lazzara R, Hope RR: Re-entrant ventricular arrhythmias in the late infarction period. 4. Mechanism of action of lidocaine. Circulation 56:395, 1977.

31. Greenspan AM, Horowitz LN, Spielman SR, Josephson ME: Large doses of procainamide therapy for ventricular tachyarrhythmia. Am J Cardiol 46:453, 1980.

32. Michelson El, Spear JF, Moore EN: Effects of procainamide on strength-interval relations in normal and chronically infarcted canine myocardium. Am J Cardiol 47:1223, 1981. 